\title{
Physicochemical properties of low-amylose yam (Dioscorea spp.) starches and its impact on $\alpha$ - amylase degradation in vitro
}

\author{
Cliff Kelvin Riley ${ }^{1,2, *}$, Perceval Stephen Bahado-Singh ${ }^{2}$, Andrew O'Brien Wheatley ${ }^{2,3}$, \\ Helen Nosakhare Asemota ${ }^{2,3}$ \\ ${ }^{1}$ College of Health Sciences, University of Technology, Jamaica \\ ${ }^{2}$ Biotechnology Centre, University of the West Indies, Mona Campus, Kingston Jamaica \\ ${ }^{3}$ Department of Basic Medical Sciences (Biochemistry), University of the West Indies, Mona Campus, Kingston Jamaica
}

\section{Email address:}

cliff.riley@yahoo.com (C. K. Riley)

To cite this article:

Cliff Kelvin Riley, Perceval Stephen Bahado-Singh, Andrew O’Brien Wheatley, Helen Nosakhare Asemota. Physicochemical Properties of Low-Amylose Yam (Dioscorea Spp.) Starches and its Impact on $\alpha$ - Amylase Degradation in Vitro. International Journal of Nutrition and Food Sciences. Vol. 3, No. 5, 2014, pp. 448-454. doi: 10.11648/j.ijnfs.20140305.23

\begin{abstract}
Starches from four low-amylose yam cultivars, cv.Chinese yam, Bitter yam, Yampie and Akam cultivated in Jamaica were extracted and the relationship between physicochemical properties and in vitro digestibility investigated. A direct correlation between starch physicochemical properties and digestibility of the low- amylose starches was observed. Chinese and Bitter yam starches with the lowest amylose content were found to have the highest digestibility in vitro (21.27 \pm $0.01 \%$ and $18.11 \pm 0.02 \%$ respectively), while Akam and Yampie starches with higher amylose content had significantly lower percentage digestibility $(\mathrm{p}<0.05)$. The mean granular diameter of the starches ranged from $5.4 \mu \mathrm{m}$ for Chinese yam to $29.58 \mu \mathrm{m}$ for Yampie. The variations observed in the granular size may have influenced the surface properties of the starches, as Chinese yam was found to have the largest specific surface area $(625.91 \mathrm{~m} 2 / \mathrm{kg})$ while Yampie had the lowest (117. 4 $\mathrm{m} 2 / \mathrm{kg}$ ). The digestibility of the starches was also influenced by granule diameter, specific surface area, crystalline pattern and surface-no. mean of the starches studied.
\end{abstract}

Keywords: $\alpha$-Amylase, Low-Amylose, Crystallinity, Specific Surface Area, Starch, Yam (Dioscorea Spp)

\section{Introduction}

Yam tubers (Dioscorea spp) are consumed as a source of digestible carbohydrate by millions of people in the tropical and subtropical regions and in some European Countries [1]. Yam tubers are classified as either edible or non-edible, where non-edible cultivars are used primarily for their medicinal properties. Research shows that wild/non-edible yams may be used in the treatment of hypercholesteremia, menopausal symptoms [2], lipid metabolism and cardiovascular disease [3]. According to Bahado-Singh et al [4] some edible yams may be beneficial to persons living with diabetes as the glycemic index of the cooked tubers are usually low to medium.

The major nutritional component of yam is starch, accounting for approximately $70-90 \% \mathrm{w} / \mathrm{w}$ of the tuber [1]. Due to the high starch content, extensive research have been done which have revealed intra-varietal variations in their physicochemical and functional properties, among different cultivars [5-10]. In particular, variations in the amylose/amylopectin content of yam starches and their effect on starch properties and functionality were previously reported $[9,11-12]$. Studies have also shown that the differences in amylose content may illicit variations in functional characteristics such as digestibility, crystallinity, physical properties, functionality and glycemic indices [7, 13-14]. Such variations can impact on the resulting metabolic effects and susceptibility of the native starch to $\alpha$-amylase digestion $[15,16]$. Starch digestibility is of primary significance to health conscious, diabetic and hyperlipidemic individuals as starches that are highly degraded tend to illicit higher insulin demand than those that are less digestible [16]. Jenkins et al. [17] reported that easily digested starches have a higher insulin demand than the slower degrading starches. This can affect the 
sensitivity of insulin, and lead to or reduce the risk of developing type II diabetes [18].

The amylose content of yam starches has been shown to vary with cultivar, geographical location and planting season. Yam starches with amylose contents ranging between $11 \%$ and $30 \%$ have been reported (Table 1). Studies show that differences in enzymatic degradation of starches can be linked to the amylose content along with crystallinity, particle size distribution and surface area of the granules $[15,19,20]$. Other studies have shown that starch digestibility is directly affected by the physiochemical properties of the individual starches [11, $15]$.

Table 1. Amylose content of yam starches.

\begin{tabular}{|c|c|c|}
\hline Starch Species & Amylose content (\%) & Source \\
\hline \multirow{5}{*}{ D. rotundata } & $21-23$ & Farhat et al [9] \\
\hline & 20.9-24.6, & Rasper and Coursey [10] \\
\hline & $21.5-23.5$ & Moorthy and Nair [12] \\
\hline & $21-23$ & Riley et al [7] \\
\hline & 21.6 & \\
\hline \multirow{2}{*}{ D. cayenensis } & $25-29$ & Rollande-Sabate et al [6] \\
\hline & 27 & Gallant et al [27] \\
\hline \multirow{5}{*}{ D. alata } & 21,25 & Farhat et al [9] \\
\hline & $26-27$ & Rollande-Sabate et al [6] \\
\hline & 21.1 & Rasper and Coursey [10] \\
\hline & 30 & Gallant et al [27] \\
\hline & $20.1-23$ & Riley et al. [21] \\
\hline \multirow{3}{*}{ D. dumentorum } & 17 & Rollande-Sabate et al [6] \\
\hline & 14.2 & Rasper and Coursey [10] \\
\hline & 14.8 & Sibanda et al [13] \\
\hline \multirow{3}{*}{ D. esculenta } & 17 & Rollande-Sabate et al [6] \\
\hline & 15 & Rasper and Coursey [10] \\
\hline & 11 & Riley et al [7] \\
\hline D. schimperiana & 24.5 & Sibanda et al [13] \\
\hline
\end{tabular}

This study was therefore designed to investigate the relationship between the physicochemical properties of low-amylose yam starches and their digestibility in vitro.

\section{Materials and Methods}

\subsection{Materials}

Freshly harvested matured tubers (harvested 9 months after planting) of Dioscorea trifida cv. Yampie, Dioscorea bulbifera cv. Akam, Dioscorea polygonoides cv. Bitter yam, and Dioscorea esculenta cv. Chinese yam were collected from a local farm in Jamaica. The tubers were washed, peeled and diced for immediate starch extraction. All reagents used were analytical grade and sourced from Sigma-Aldrich, USA.

\subsection{Methods}

\subsubsection{Starch Isolation}

Starch was extracted following previously reported technique [21]. Batches of freshly harvested tubers $(1000 \mathrm{~g})$ were peeled, diced and homogenized in $1 \% \mathrm{NaCl}$ solution ( $9000 \mathrm{~mL}$ ) using a Waring commercial blender. The mixture was filtered through a No. 140 Fisher analytical sieve (pore diameter, $106 \mu \mathrm{m}$ ) and washed through with water. Starch granules in the combined washings were allowed to settle overnight (12 hours) at room temperature, the supernatant was decanted and the slurry centrifuged (Beckman centrifuge) at $3000 \mathrm{x}$ g for 10 minutes. The brown top layer was scraped off and the starch re-suspended in $1 \% \mathrm{w} / \mathrm{v}$
Sodium Chloride solution and de-ionized water respectively and centrifuged after each washing. Starch was then dried at $60{ }^{\circ} \mathrm{C}$ until constant weight in a Gravity Compression oven (Precision Scientific, GCA Corporation, USA), milled and stored in glass containers until used.

\subsubsection{Determination of Apparent Amylose Content}

Apparent Amylose content was determined as outlined by Farhat et al. [9] with modifications [21]. The defatted Starch $(100 \mathrm{mg})$ was dispersed in ethanol $(1 \mathrm{ml})$ and $1 \mathrm{M} \mathrm{NaOH}(9$ $\mathrm{ml})$. The volume was made up to $100 \mathrm{ml}$ with distilled water and a $5 \mathrm{ml}$ aliquot transferred to a volumetric flask containing water $(25 \mathrm{ml})$. Acetic acid $(0.5 \mathrm{ml})$ and Iodine solution $(1 \mathrm{ml})$ were added and the volume made up to $50 \mathrm{ml}$ with water and optical density recorded at $620 \mathrm{~nm}$.

\subsubsection{Scanning Electron Microscopic Studies of Starch Granules}

Starch samples were sieved using a number $60(250 \mu \mathrm{m})$ Fisher Scientific sieve, mounted and coated with gold $(1 \mathrm{~nm})$ using a Polaron sputter coater and analyzed using a Philips 505 Scanning Electron Microscope (Phillips, Holland) at a magnification of $3.26 \times 10^{2}$ for Akam, Yampie and Bitter yam starches and $1.32 \times 10^{3}$ for Chinese yam Starch.

\subsubsection{Determination of Micromeritic Properties}

Starch samples were passed through a $250 \mu \mathrm{m}$ sieve. A small quantity of the powder was dispersed in liquid paraffin and a slide of the dispersion was examined on a Leica DMRME light microscope (Leica, Germany). Particle size of the starches samples were studied using an eye piece 
graticle previously calibrated with a stage micrometer [22, 23]. At least 500 granules were measured from each sample.

The projected mean granule diameter was calculated using the statistical equation:

$$
\bar{d}=\frac{\sum n d}{\sum n}
$$

Where $\mathrm{d}$ is granule diameter falling within a defined size range and $\mathrm{n}$ is the frequency number in the respective size range.

\subsubsection{Determination of Specific Surface Area}

The specific surface area of the starch granules was calculated using the equation of a sphere:

$$
S_{w}=\frac{6}{\rho d_{v s}}
$$

Where $\rho$ is the density of the granules and $d_{v s}$ the volume to surface ratio.

\subsubsection{Determination of Starch Crystalline Form}

Crystalline pattern of yam (Dioscorea spp.) starches were determined by the method of Farhat et al. [9]. X-ray spectra of starch samples were recorded at $2 \theta$ angles from $4^{\circ}-38^{\circ}$ with a step size of $0.005^{\circ}$ at $25^{\circ} \mathrm{C}$ using a Bruker D5005 $\mathrm{X}$-ray diffractometer. Potato, corn and pea starches were used as reference standards.

Table 2. Percentage in vitro digestibility and amylose content of yam starches (dry weight).

\begin{tabular}{lll}
\hline Starch Source & Amylose Content (\%) & In vitro Digestibility (\%) \\
\hline Yampie & $12.58 \pm 0.70^{\mathrm{d}}$ & $17.45 \pm 0.01^{\mathrm{c}}$ \\
Akam & $19.74 \pm 0.70^{\mathrm{c}}$ & $15.78 \pm 0.03^{\mathrm{d}}$ \\
Bitter Yam & $11.97 \pm 0.80^{\mathrm{b}}$ & $18.11 \pm 0.02^{\mathrm{b}}$ \\
Chinese Yam & $11.14 \pm 0.30^{\mathrm{a}}$ & $21.27 \pm 0.01^{\mathrm{a}}$ \\
\hline
\end{tabular}

Mean $\pm \operatorname{SEM}(n=6)$. Superscripts sharing different letters are significantly different $(\mathrm{p}<0.05)$.

\subsubsection{Determination of Percentage in Vitro Digestion}

Percentage digestion was determined in vitro as outlined by Hassan and West [24] with slight modifications. Starch $(10 \mathrm{mg})$ was suspended in porcine pancreatic $\alpha$-amylase solution ( $5 \mathrm{ml}$ of a $60 \mathrm{mg} / \mathrm{ml}$ solution), buffered with $0.05 \mathrm{M}$ citric acid - sodium acetate buffer and $0.02 \% \mathrm{CaCl}_{2}$ at $\mathrm{pH}$ 5.5. Samples were incubated for $24 \mathrm{hrs}$ at $40{ }^{\circ} \mathrm{C}$ and the reaction stopped by addition of $(1 \mathrm{ml}$ of a $1 \mathrm{M} \mathrm{NaOH}$ solution), followed by centrifugation at $2000 \mathrm{rpm}$ for 10 minutes. Reducing sugars were determined by the method of Nelson [25].

\subsubsection{Determination of Yam Starch Caloric Value}

The caloric values of the yam starches were determined using a Parr bomb calorimeter (Parr Instrument Co. Model 1261) as outlined by Glover et al. [26]. Starch pellets (1 gram) were prepared using a pellet press then carefully placed in a calibrated bomb calorimeter (calibrated with benzoic acid). Fuse wire $(10 \mathrm{~mm})$ was threaded through the electrodes and configured to a point directly above and resting on the starch pellet in the bomb head. One milliliter $(1 \mathrm{~mL})$ of water was then added to the bottom of the bomb, and the bomb head lowered into the bomb. The sealed bomb was then pressurized with pure oxygen to 30 atmosphere followed by equilibration (bomb and calorimeter) and ignition. After combustion the bomb was slowly depressurized, washed with distilled water and titrated against $0.07 \mathrm{~N}$ sodium carbonate.

\subsubsection{Statistical Analysis}

Samples were analyzed in replicates of 6 and evaluated using the One-Way ANOVA Duncan's t-test $(\mathrm{p}<0.05)$.

\section{Results and Discussion}

The yam starches studied had amylose contents ranging from $11.14 \%$ to $19.74 \%$ (Table 2). Previous studies have shown that the amylose content of yam starches can be as high as $30 \%[9,27]$. Of the four low-amylose yam starches studied, Chinese yam was found to have the lowest amylose content (11.14\%) while Akam, an aerial tuber, the highest $(19.74 \%)$. It is unclear as to what factors influences intra-varietal variations in amylose content. However, studies have shown that such disparities in the amylose/amylopection ratio may be due to genetic variations and environmental conditions $[9,28]$. It has been further postulated that amylose content may be affected by the expression of the amylose extender gene, where starches from sources with high expression of the gene would have higher amylose contents than those with lower gene expression $[28,29]$. It was also reported that a genetic variation in amylose content is due to allelic difference at the $W x-B 1$ locus on Chromosome 4A in sorghum starches [29].

A correlation between the amylose content, starch granule size distribution, crystalline structure and percentage digestibility in vitro was observed. Starches with low amylose content such as Chinese yam and Bitter yam were found to display type $\mathrm{C}$ or Type-A crystalline structures and were more susceptible to $\alpha$-amylase digestion, while those with higher amylose content conformed to the type B structure and were less susceptible to $\alpha$-amylase digestion in vitro. Padmanabhan and Lasome [30] reported similar correlation between amylose content and starch crystallinity. Low-amylose cassava starches were found to be more crystalline thus conforming to type A or type $\mathrm{C}$ structure while high amylose varieties were more amorphous and exhibited the type-B structure. Previous studies have shown that starches with high amylose content tend be more resistant to enzymatic degradation resulting in lower degrees of digestion in vitro [19]. Mir et al. [31] reported that starches with lower amylose content were more accessible by digestive enzymes and generally had lower quantities of resistant starch. As such, low amylose starches were more digestible than their counterparts with higher amylose 
content. The relationship between amylose content, post-prandial glucose concentrations and emptying of human gastrointestinal tract were also reported [32, 19]. It has been reported that starches with low amylose content illicit higher blood glucose concentrations and slower gastric empting rates. It is important to note however that other fundamental properties such as granule size and size distribution, degree of crystallinity, granule porosity, specific surface area, polymerisation, starch form (native vs. modified) and non-starch components such as lipids also influence starch digestibility [33, 34].

Table 3. Granule shape, crystalline type and caloric value of yam (Dioscorea spp) starches.

\begin{tabular}{llll}
\hline Starch Source & $\begin{array}{l}\text { Granule } \\
\text { Shape }\end{array}$ & $\begin{array}{l}\text { Crystalline } \\
\text { Type }\end{array}$ & $\begin{array}{l}\text { Caloric Value } \\
\text { (kcal/100 gram) }\end{array}$ \\
\hline Yampie & Polyhedral & $\mathrm{B}$ & $347.71 \pm 5.01^{\mathrm{a}}$ \\
Akam & Triangular & $\mathrm{B}$ & $351.13 \pm 8.18^{\mathrm{a}}$ \\
Bitter Yam & Round & $\mathrm{A}$ & $363.15 \pm 9.01^{\mathrm{b}}$ \\
Chinese Yam & Ellipsoid & $\mathrm{C}$ & $349.82 \pm 9.29^{\mathrm{a}}$ \\
\hline
\end{tabular}

Mean \pm SEM $(n=6)$. Superscripts sharing different letters are significantly different $(\mathrm{p}<0.05)$

The low-amylose yam starches studied displayed three distinct crystalline patterns/structures (Table 3, Fig. 1). $\mathrm{X}$-ray diffraction analysis revealed that both Yampie and
Akam exhibited the open hydrated hexagonal crystallite (type-B), while Bitter yam displayed the staggered monoclinic crystallite (type-A) and Chinese yam an intermediate crystalline form (type- $\mathrm{C}$ ). It has been reported that tuber starches usually exhibit the Type - B structure as a result of high amylose content or low amylose/amylopectin ratio [9]. On the other hand starches with low amylose/ high amylopectin contents are of either the type-A or the intermediate type-C form [35]. Studies have shown that the amylose/amylopectin ratio can impact on the percentage starch crystallinity thereby influencing the crystalline pattern $[30,35]$. The crystalline patterns of the starches studied may correlate with the percentage amylose digestion obtained as that the type-C and type-A starches were found to be more digestible than the type-B forms under in vitro conditions. This is could be due to the granular packing of low amylose/high amylopectin starch as the high number of branch chains provides more access points for degradation. Similar findings were reported by Noda et al. [34]

The caloric value of the starches studied ranged from $347.71 \mathrm{kcal} / 100 \mathrm{~g}-363.15 \mathrm{kcal} / 100 \mathrm{~g}$ starch (Table 3). The results obtained were within the expected range for starches (300 kcal/100 g- $400 \mathrm{kcal} / 100 \mathrm{~g}$ starch). Yampie starch was found to have the lowest caloric value $(347.71 \mathrm{kcal} / 100 \mathrm{~g})$ while Bitter yam was found to have the highest (363.15 $\mathrm{kcal} / 100 \mathrm{~g})$. No direct correlation between physicochemical properties of the low-amylose starches and caloric value was observed.

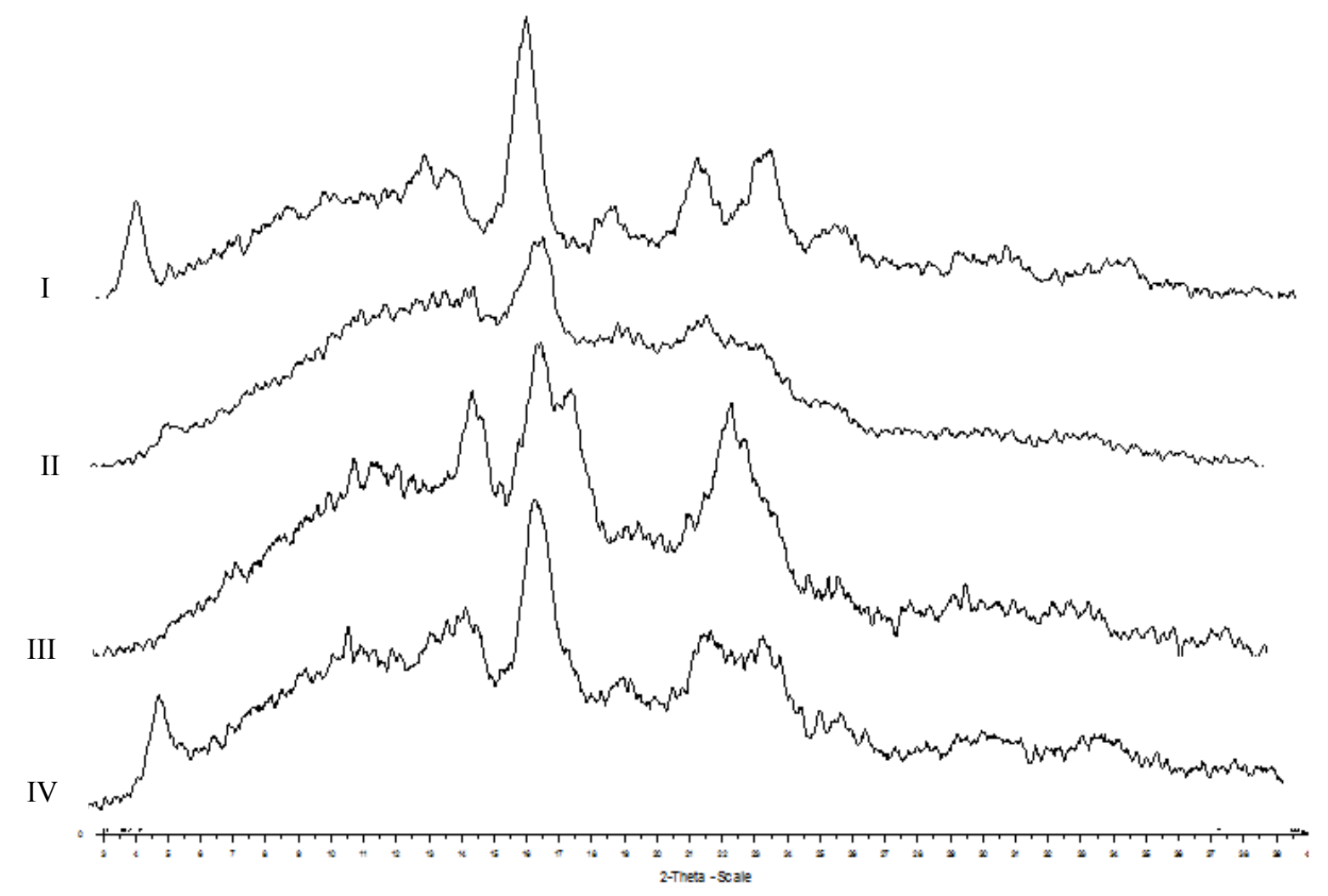

Figure 1. X-Ray Diffraction Pattern of (I) Akam, (II) Chinese yam starches, (III) Bitter yam, and (IV)Yampie 
Table 4. Micromeritic properties of yam (Dioscorea spp.) starches.

\begin{tabular}{lllll}
\hline Yam cultivar & Projected mean diameter $(\boldsymbol{\mu m})$ & $\begin{array}{l}\text { Geometric mean Diameter } \\
(\boldsymbol{\mu m})\end{array}$ & Surface - no. mean $\left(\boldsymbol{\mu m}{ }^{2}\right)$ & Specific surface area $\left(\mathbf{m}^{2} / \mathbf{k g}\right)$ \\
\hline Yampie & $29.58^{d}$ & $12.87^{\mathrm{d}}$ & $30.13^{\mathrm{d}}$ & $124.11^{c}$ \\
Akam & $27.06^{c}$ & $10.37^{\mathrm{c}}$ & $27.71^{\mathrm{c}}$ & $136.78^{c}$ \\
Bitter Yam & $15.30^{b}$ & $11.58^{\mathrm{b}}$ & $15.71^{\mathrm{b}}$ & $258.76^{\mathrm{b}}$ \\
Chinese Yam & $5.41^{a}$ & $7.789^{\mathrm{a}}$ & $5.67^{\mathrm{a}}$ & $626.91^{a}$ \\
\hline
\end{tabular}

Mean \pm SEM $(n=6)$. Superscripts sharing differen $1 \quad$ I $\quad s$ are significantly different $(p<0.05)$

II

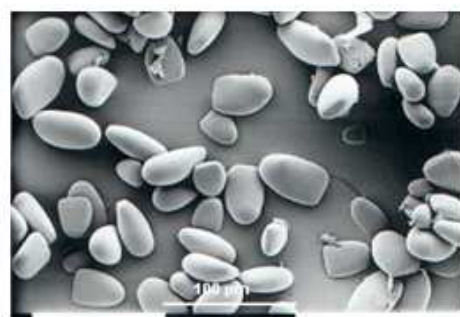

III

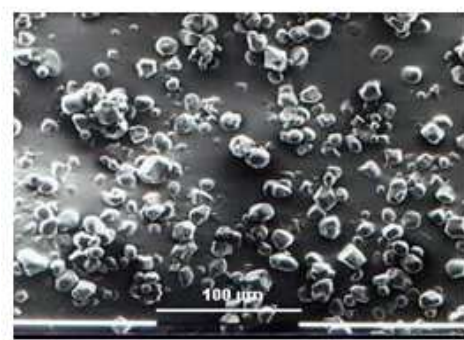

Figure 2. Scanning Electron micrographs of (I) Yampie, (II) Akam, (III) Bitter yam, and (IV) Chinese yam starches.

Microscopic and micromeritic analyses of the starch granules highlighted the differences in granular size, size distribution, shape, surface area and surface-no. mean (Table 4 and Fig. 2). Chinese yam starch had the smallest mean granule diameter, geometric diameter, surface-no. mean and highest specific surface area while Akam was the inverse. The percentage enzymatic degradation was found to correlate with starch particle size and specific surface area. Chinese Yam, Bitter Yam and Yampie starches were found to be the most susceptible to $\alpha$-amylase digestion under in vitro conditions while Akam was the least susceptible (Table. $2)$. The degree of $\alpha$-amylase digestion increased with decrease in mean and geometric granular diameter, and increased specific surface area. Similar correlations between granular size and digestibility have been reported [34, 36, 37].

The results from the study imply significant variations in the physicochemical properties among the four low-amylose yam cultivars studied. The in vitro digestibility of the starches was found to correlate with the starch crystalline form, mean and geometric granule diameter, specific surface area and amylose content. This further implies that care should be taken when consuming or utilising these low-amylose yam starches in food preparations as they are digested at a faster rate when compared to high amylose types. This could result in rapid increases in the postprandial blood glucose leading to greater insulin demand and other endocrine responses when consumed [38]. Additionally, one must also consider the caloric value of the starches when

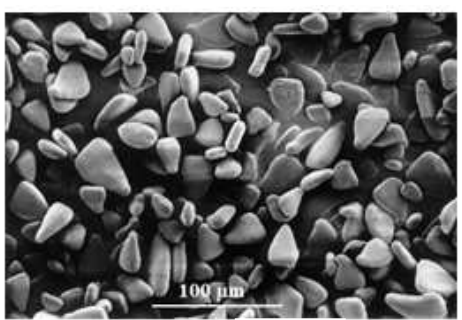

IV

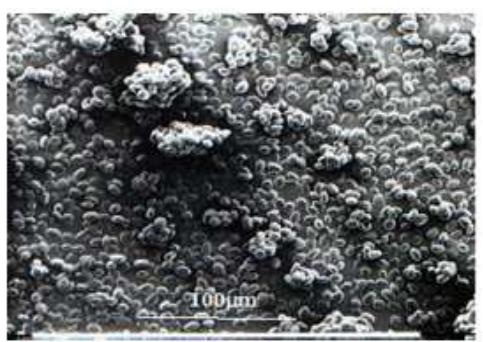

formulating nutritional plans.

\section{Conclusions}

The physicochemical properties of the low-amylose yam starches studied varied significantly $(p<0.05)$. A correlation between amylose content, crystalline form, granule size and specific surface area was observed. In addition to this, starches with small granule diameters, of type-C or type-A crystalline form and high specific surface area were the most susceptible to $\alpha$-amylase digestion in vitro. No direct correlation between amylose content and caloric value was observed.

\section{Acknowledgements}

The authors are grateful to the School of Graduate Studies and Research, University of the West Indies (Mona Campus) and the School of Graduate Studies, Research and Entrepreneurship, University of Technology Jamaica for financial support.

\section{References}

[1] Asemota HN, and Osagie AU. (1993). Carbohydrate metabolism in stored yam tubers: Contribution of starch breakdown, glycolysis and pentose phosphate pathway. In: Osuji, G (Ed), Advances in Yam Research (pp 135-44). Texas: Prairie View AandM University. 
[2] Komesaroff PA, Black CV, Cable V, and Sudhir K. (2001). Effects of wild yam extract on menopausal symptoms, lipids and sex hormones in healthy menopausal women. Climacteric 4: 144-50.

[3] Wu WH, Liu LY, Chung CJ, Jou HJ, Wang TA. (2005). Estrogenic effect of yam ingestion in healthy postmenopausal women. J Am Coll Nutr 24: 235-43.

[4] Bahado-Singh PS, Wheatley AO, Ahmad MH, Morrison EYStA, and Asemota HN. (2006). Food processing methods influence the glycemic indices of some commonly eaten West Indies carbohydrate-rich foods. Br J Nutr 96: 476-448.

[5] Akissoe N, Mestres C, Handschin S, Gibert O, Hounhouigan $\mathrm{J}$, and Nago M. Microstructure and physico-chemical bases of textural quality of yam products. (2011). Food Science and Technology 44: 321-329.

[6] Rolland-Sabate A, Amani NG, Dufour D, Guilois S, Colonna P. (2003) Macromolecular characteristics of ten yam (Dioscorea spp) starches. J Sci Food Agri 83: 927-936.

[7] Riley CK, Bahado-Singh PS. Wheatley AO, Ahmad M, Asemota HN. (2008). Relationship between the physiochemical properties of starches and the glycemic index of some Jamaican yams (Dioscorea spp.). Molecular Nutrition and Food Research 52: 1372 - 1376.

[8] Tetchi F, Rolland-Sabaté A, Amani N, Colonna P. (2007). Molecular and physicochemical characterisation of starches from yam, cocoyam, cassava, sweet potato and ginger produced in the Ivory Coast. J Sci Food Agric 87: 1906-1916.

[9] Farhat IA, Oguntona T, and Roger NJ. (1999). Characterisation of starches from West African yam. J Sci Food Agric 79: 2105-1212.

[10] Rasper V, Coursey DG. (1967) Properties of some West African yams. J Sci Food Agric 18: 240-244.

[11] Lape IM, and Treche S. (1994). Nutritional quality of yam (Dioscorea Dumentorum and Dioscorea rotundata) flours for growing rats. J Sci Food Agric 66: 447-55.

[12] Moorthy SN, and Nair SG. (1989). Studies on Dioscorea rotundata starch properties. Starch/Starke 41: 81-83.

[13] Sibanda S, Sibanda S, and Sychawska B. (2000) A comparative study of wild yam starch from Dioscorea schimperiana. J Appl Sci South Africa 6: 79-86.

[14] Behall KM, Scholfield DJ, and Canary J. (1988a). Diets containing high amylose $v s$ amylopectin starch: effects on metabolic variables in human subjects. Am J Clin Nutr 47: 428-32.

[15] Regmi P, Metzler-Zebeli U, Gänzle M, van Kempen T, Zijlstra R. (2011). Starch with high amylose content and low in vitro digestibility increases intestinal nutrient flow and microbial fermentation and selectively promotes bifidobacteria in pigs. J Nutr 14: 1273-80.

[16] Bornet FRJ, Fontvieille AM, Rizkalla S, Colona P, Blayo A, Mercier C, and Slama G. (1989). Insulin and glycemic responses in healthy humans to native starches processed in different ways: correlation with in vitro a-amylase hydrolysis. Am J Clin Nutr 50: 315-23.

[17] Jenkins DJ, Taylor RH, and Wolever TMS. (1982). Relationship between the rate of digestion of foods and post-prandial glycaemia. Diabetologia 23: 477-84.
[18] Salmeron J, Ascherico A, Rimm EB, Colditz GA, Speigelman D, Jenkins DJ, Stampfer M, Wing JAL, Willet WC. (1997). Dietary fibre, glycemic load, and risk of NIDDM in men. Diabetes Care 20: 545-550.

[19] Behall KM, Scholfield DJ, and Canary J. (1988b). Effect of starch structure on glucose and insulin responses in adults. Am J Clin Nutr 47: 428-432.

[20] Heaton KW, Marcus SN, Emment PM, and Bolton CH. (1988). Particle size of wheat, maize, and oat test meals: effects on plasma glucose and insulin responses and on the rate of starch digestion in vitro. Am J Clin Nutr 47: 675-82.

[21] Riley CK, Wheatley AO, Asemota HN. (2006). Isolation and Characterization of starches from eight Dioscorea alata cultivars grown in Jamaica. African Journal of Biotechnology 5: 1528-1536.

[22] Florence A T. (1986). Analysis of drugs in the solid state. In: Beckett, A. H. and Stenlake, J.B. (Eds), Practical Pharmaceutical Chemistry. 3rd ed, vol.2 (pp 41). Delhi, India: CBS Publisher.

[23] Washington C. (1992). Particle size analysis In: Horwood, E. (Ed), Pharmaceutics and other industries - theory and practice (pp 215-231) New York: Ellis Horwood Ltd.

[24] Hassan HS, and West L. (1992). Studies on starch granules digestion by $\alpha$-amylase. Starch/Starke 44: 61-63.

[25] Nelson N.J. (1994). A photometric adaptation of the Somogyi method for the determination of glucose. J Biol Chem 153:375-380.

[26] Glover, DC, Devries DR, Wright RA, and Davis DA. (2010). Sample Preparation Techniques for Determination of Fish Energy Density via Bomb Calorimetry: An Evaluation Using Largemouth Bass. Transactions of the American Fisheries Society 139: 671-75.

[27] Gallant DJ, Bewa H, Buy QH, Szylit O, and Sealy L. (1982). On ultra structural and nutritional aspects of some tropical tuber crops. Starch/Staerke 34: 255-62.

[28] Araki E, Miura H, and Sawada S. (1999). Identification of genetic loci affecting amylose content and agronomic traits on chromosome 4A of wheat. Theoretical and Applied Genetics 98: 977-984.

[29] McDonald AML, Stark JR, Morrison WR, Ellis RP. (1991). The composition of starch granules from developing barley genotypes. J Cereal Sci 13: 93-112.

[30] Padmanabhan S, and Lonsane BK (1992). Comparative physio-chemical and functional properties of cassava starches obtained by conventional and enzyme-integrated conventional techniques. Starch/Starke 44: 328-331.

[31] Mir JA, Srikaeo K, and García J. (2013). Effects of amylose and resistant starch on starch digestibility of rice flours and starches. International Food Research Journal 20: 1329-1335.

[32] Frei M, Siddhuraju P, and Becker K. (2003). Studies on the in vitro starch digestibility and the glycemic index of six different indigenous rice cultivars from the Philippines. Food Chemistry 83: 395-402.

[33] Tester RF, Qi X, Karkalas J. (2006). Hydrolysis of native starches with amylases. Animal Feed Science and Technology 130: 39-54. 
[34] Noda T, Takigawa S, Matsuura-Endo C, Suzuki T, Hashimoto N, Kottearachchi NS, Yamauchi H, and Zaidul ISM. (2008). Factors affecting the digestibility of raw and gelatinized potato starches. Food Chemistry 110: 465-470.

[35] Parker R, and Ring SG. (2001). Aspects of physical chemistry of starch. J Cereal Sci 34: 1-17.

[36] Cone JW, and Wolters GE. (1990). Some properties and degradability of isolated starch granules. Starch/Starke 42: 298- 301
[37] Franco MLC, Preto SJR, and Ciacco CF. (1992). Factors that affect the enzymatic degradation of natural starch granules-Effect of the size of the granule. Starch/Starke 32: 113-116.

[38] Wolever TMS, Jenkins DJA, Vuksan V, Jenkins AL, Buckley GC, Wong GS, Josse, RG. (1992). Beneficial effect of a low-glycaemic index diet in type 2 diabetes, Diabet Med 9: 451-458. 